\title{
Stratospheric semi-decadal oscillations in NCEP data
}

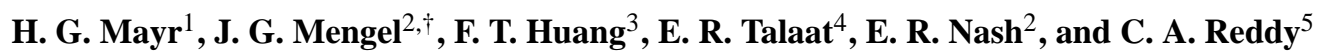 \\ ${ }^{1}$ NASA, Goddard Space Flight Center, Greenbelt, MD, USA \\ ${ }^{2}$ Science Systems and Applications Inc., Lanham, MD, USA \\ ${ }^{3}$ University of Maryland, Baltimore, MD, USA \\ ${ }^{4}$ Applied Physics Laboratory, Johns Hopkins University, Laurel, MD, USA \\ ${ }^{5}$ Langhorne, PA, USA \\ $\dagger$ deceased
}

Received: 23 November 2007 - Revised: 29 April 2008 - Accepted: 16 June 2008 - Published: 1 August 2008

\begin{abstract}
An analysis of the National Centers for Environmental Prediction (NCEP)/National Center for Atmospheric Research (NCAR) data is presented to provide a more complete description of the stratospheric 5-year semi-decadal (SD) oscillation (Mayr et al., 2007). The zonal-mean temperature and zonal wind data from the Atmospheric Research R-1 analysis are employed, covering the years from 1962 to 2002 in the altitude range from 10 to $30 \mathrm{~km}$. For diagnostic purposes, the data are separated into the hemispherically symmetric and anti-symmetric components, and spectral analysis is applied to identify the signatures of the SD oscillations. Through the synthesis or filtering of spectral features, the SD modulations of the annual oscillation (AO) and quasi-biennial oscillation (QBO) are delineated. In agreement with the earlier findings, the magnitude of the SD oscillation is more pronounced when the 30-month QBO dominates during the years from 1975 to 1995 . This is consistent with results from a numerical model, which shows that such a QBO generates the SD oscillation through interaction with the 12-month AO. In the zonal winds, the SD oscillation in the NCEP data is confined to equatorial latitudes, where it modulates the symmetric $\mathrm{AO}$ and $\mathrm{QBO}$ by about $5 \mathrm{~m} / \mathrm{s}$ below $30 \mathrm{~km}$. In the temperature data, the effect is also seen around the equator, but it is much larger at polar latitudes where the SD oscillation produces variations as large as $2 \mathrm{~K}$. Our data analysis indicates that the SD oscillation is mainly hemispherically symmetric, and it appears to originate at equatorial latitudes where most of the energy resides.
\end{abstract}

Keywords. Meteorology and atmospheric dynamics (Climatology; Middle atmosphere dynamics; Waves and tides)

Correspondence to: $\mathrm{H}$. G. Mayr

(hans.g.mayr@nasa.gov)

\section{Introduction}

The equatorial region of the middle atmosphere is controlled to a large extent by wave mean flow interactions that involve the mean zonal circulation. It was demonstrated by Lindzen and Holton (1968), Holton and Lindzen (1972) and others (e.g. Plumb, 1977; Dunkerton, 1985) that the stratospheric quasi-biennial oscillation (QBO), discovered by Reed (1965) and discussed by Pascoe et al. (2005) and Baldwin et al. (2001), can be generated with eastward propagating Kelvin waves and westward propagating Rossby gravity waves. The theory of Lindzen and Holton was applied by Dunkerton (1979) and Hamilton (1986) to simulate also the semi-annual oscillation (SAO) of the zonal circulation, which dominates in the upper stratosphere and lower mesosphere at around $50 \mathrm{~km}$ (Hirota, 1980). While it is generally accepted that wave mean flow interactions are required to generate the above equatorial oscillations, more recent modeling studies have shown that small-scale gravity waves (GW) are also likely involved (e.g. Hitchman and Leovy, 1988; Mengel et al., 1995; Takahashi, 1999; Hamilton et al., 2001; Giorgetta et al., 2002). That GWs are of central importance for the dynamics of the upper mesosphere had earlier been recognized by Lindzen (1981) and Dunkerton (1982).

In their seminal theory for the QBO, Lindzen and Holton (1968) emphasized that wave interactions are very effective in generating flow oscillations at equatorial latitudes. Since the Coriolis force vanishes at low latitudes (at the equator exactly), the meridional winds are barely involved in redistributing the flow momentum, and the wave source is balanced mainly by viscous dissipation. Away from the equator, the meridional circulation increasingly comes into play to dissipate and redistribute the zonal flow momentum. As a result, the QBO zonal winds peak at the equator, as observed, even in models that apply a latitude independent wave source (e.g. Mengel et al., 1995); and Haynes (1998) provided a detailed discussion of the process involved.

Published by Copernicus Publications on behalf of the European Geosciences Union. 
For the wave forcing to be so effective at equatorial latitudes, it is essential that the zonal flow is hemispherically symmetric, and the observed QBO and SAO show that to first order. Due to critical level absorption, the wave momentum source varies with the flow velocity. Under symmetric conditions, the waves propagating up then reinforce each other to produce a coherent oscillation around the equator. When the flow is hemispherically anti-symmetric in contrast, the opposing momentum sources in the two hemispheres tend to cancel each other across the equator in the presence of horizontal diffusion.

In a recent study of the solar cycle (SC) effect (Mayr et al., 2005), it was shown that the model produced a hemispherically symmetric annual oscillation (AO), which is modulated by the SC and is confined in the zonal winds to low latitudes like the QBO and SAO. The symmetric AO is induced in the model by the anti-symmetric component of the SC forcing, and it is amplified by wave mean flow interactions around the equator.

Observed annual oscillations (AO) at low latitudes have been documented for the temperature variations (e.g. Reed and Vlcek, 1969; Pawson and Fiorino, 1998) and the zonal winds (e.g. Reddy and Reddi, 1986; Reddy et al., 1986; Reddy and Vijayan, 1993; Fleming et al., 1990). Driven to first order by the seasonal and hemispherical differences in heating, the AO is anti-symmetric to first order. This produces significant variations across the equator to mask the weaker symmetric AO that can develop at low latitudes.

Mayr et al. (2007) carried out an analysis of data supplied by the National Centers for Environmental Prediction (NCEP), which revealed a pronounced AO that is hemispherically symmetric. The NCEP data also show that this particular AO is modulated by a 5 -year semi-decadal (SD) oscillation, which appears to be generated by a 30-month QBO as predicted in a 2-D modeling study (Mayr et al., 2000). Another possible source of SD oscillations is the El Niño/Southern Oscillation (ENSO), which can generate inter-annual climate variations with periods from 3 to 8 years (e.g. Wang, 1995; Trenberth, 1997; Trenberth et al., 2005).

In the present paper, we expand on the earlier analysis of NCEP data by documenting more fully the SD modulations of the $\mathrm{AO}$ and QBO zonal winds and temperatures. In Sect. 2, we briefly describe the data and the analysis. In Sect. 3, we discuss the spectra that describe the hemispherically symmetric and anti-symmetric components of the zonal wind and temperature data; and we show model results to provide understanding. In Sect. 3, we discuss the inferred SD modulation of the AO, which appears only in the symmetric component and extends in the temperature with significant amplitudes to the polar region. In Sect. 4, we discuss the SD modulation of the QBO that reveals similar properties. In Sect. 5, we summarize the results and present the conclusion.

\section{NCEP reanalysis R-1 data}

In our study, we employ the data from the National Centers for Environmental Prediction (NCEP)/National Center from the Atmospheric Research R-1 reanalysis (Kalney et al., 1996), which cover the years from 1958 to the present. The R-1 data extend from the surface to $10 \mathrm{hPa}$ (approximately $31 \mathrm{~km}$ ) and are spaced at 2.5 degrees in latitude. We use the zonal-mean zonal winds and temperatures.

As discussed by Kalney et al. (1996) and Kalney (2003), the R-1 data represent mainly balloon-borne radiosonde observations, which have been assimilated in GCM simulations. Nadir sounding satellite measurements introduced after 1978 improved the global coverage, but Huesmann and Hitchman $(2001,2003)$ have shown that the observations produced a jump in the NCEP temperatures in particular near the tropopause and at around $31 \mathrm{~km}$. The NCEP data have been applied in a wide range of scientific studies, dealing for example with anthropogenic effects on the Earth' climate (Levitus et al., 2001), the solar cycle effect in the QBO temperature variations of the lower stratosphere (Salby and Callaghan, 2006), the longitudinal variations of the annular mode in the Northern Hemisphere (Thompson and Wallace, 2001), and the variability of atmospheric heat sources (Yanai and Tomita, 1998), to mention a few.

In our analysis, we delineate the NCEP data in terms of their hemispherically symmetric and anti-symmetric components. The data in the Northern and Southern Hemispheres, $D_{n}$ and $D_{s}$, respectively, are split up into the symmetric (S) and anti-symmetric (A) elements by computing, respectively, $\mathrm{DS}=\left(D_{n}+D_{s}\right) / 2$ and $\mathrm{DA}_{n}=\left(D_{n}-D_{s}\right) / 2, \mathrm{DA}_{s}=\left(D_{s}-D_{n}\right) / 2$. The DS component then describes the symmetric AO with the QBO and SAO, which tend to peak at the equator, while $\mathrm{DA}_{n}=-\mathrm{DA}_{s}$ describes to first order the dominant antisymmetric AO with opposite phase in the two hemispheres, which vanishes at the equator.

Applying Fourier analysis, the hemispherically symmetric and anti-symmetric spectra are derived to identify the AO, QBO, and long-term signatures in the lower stratosphere (10 to $30 \mathrm{~km})$. The relevant spectral features are then synthesized (filtered) to reveal the oscillations embedded in the data.

\section{Zonal wind and temperature spectra}

Mayr et al. (2007), referred to as MetAl, analyzed the NCEP data for the years 1965 to 2005 and 1975 to 1995 . Covering a time span of 20 years, the latter data set is unique because the 30-month QBO dominates, and we employ it also in the present analysis. For the 40-year time span, we chose a somewhat different data sample from 1962 to 2002; it supports the earlier findings to produce results that are virtually identical.

In our discussion of the zonal wind spectra, for conciseness, we refer to the Figs. 1 and 3 in MetAl, which were 


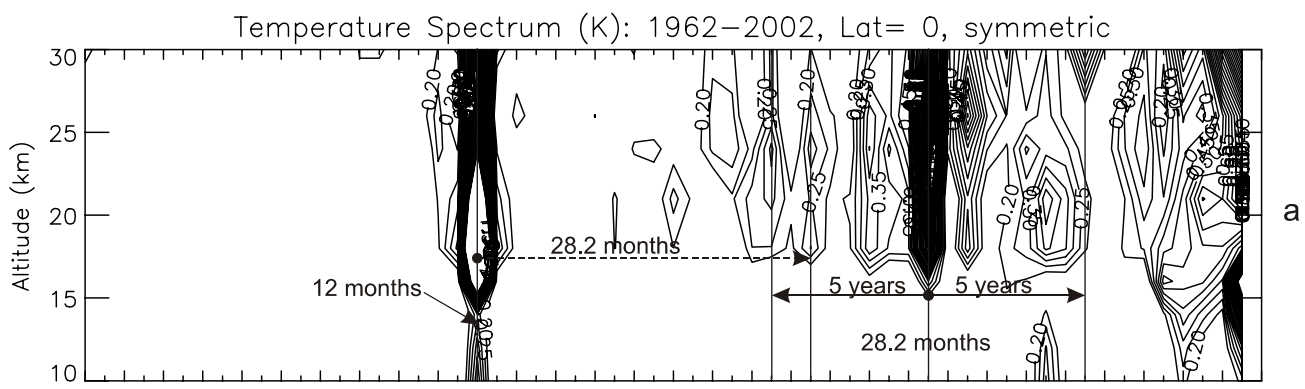

$605856545250484644424038363432302826242220181614121086 \quad 6 \quad 4 \quad 2 \quad 0$

Harmonic, $h$

[Frequency $=h / 40($ cpy $)$ ]

Temperature Spectrum (K): 1962-2002, Lat=90, symmetric
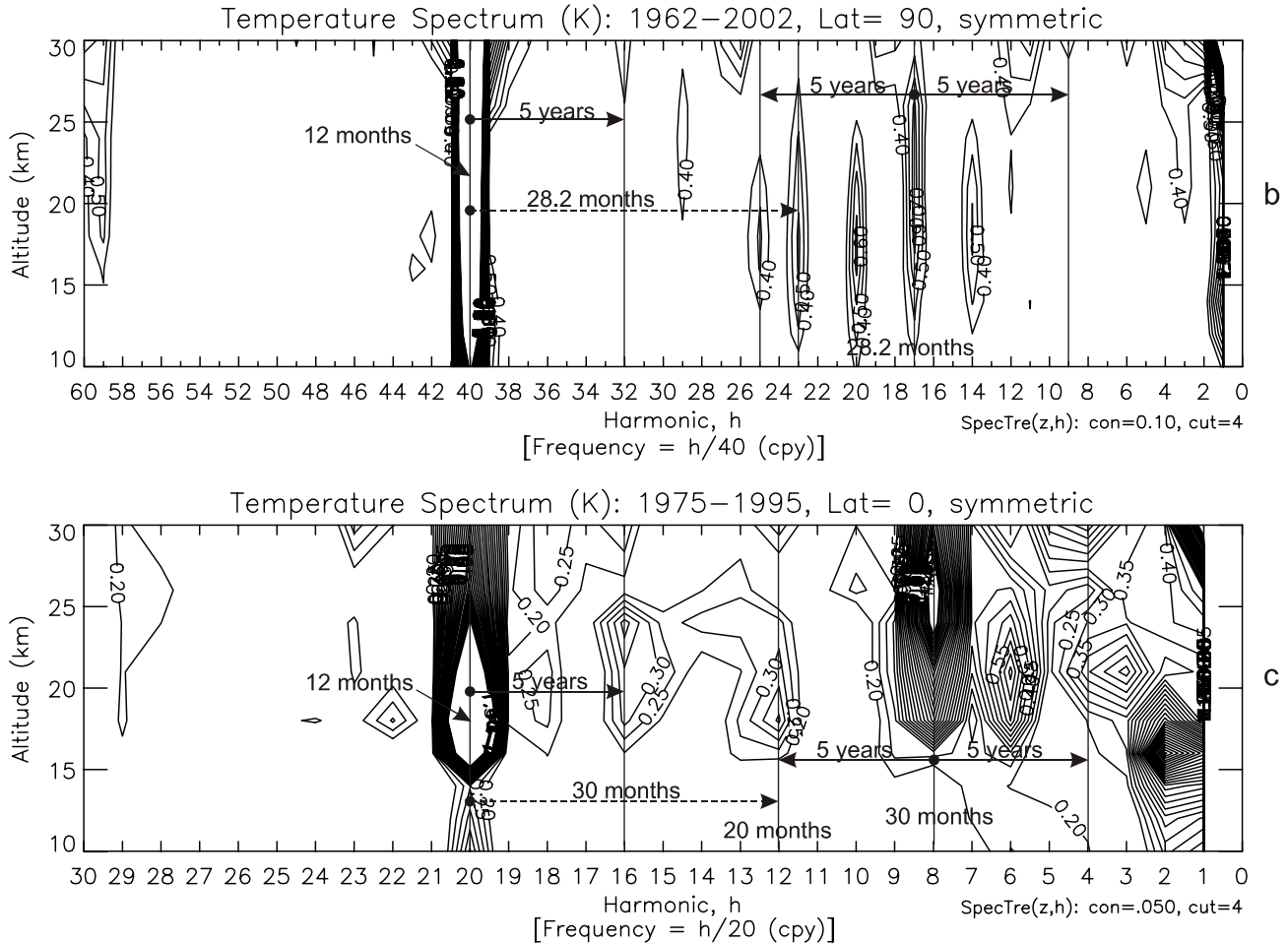

Temperature Spectrum $(K):$ 1975-1995, Lat $=90$, symmetric

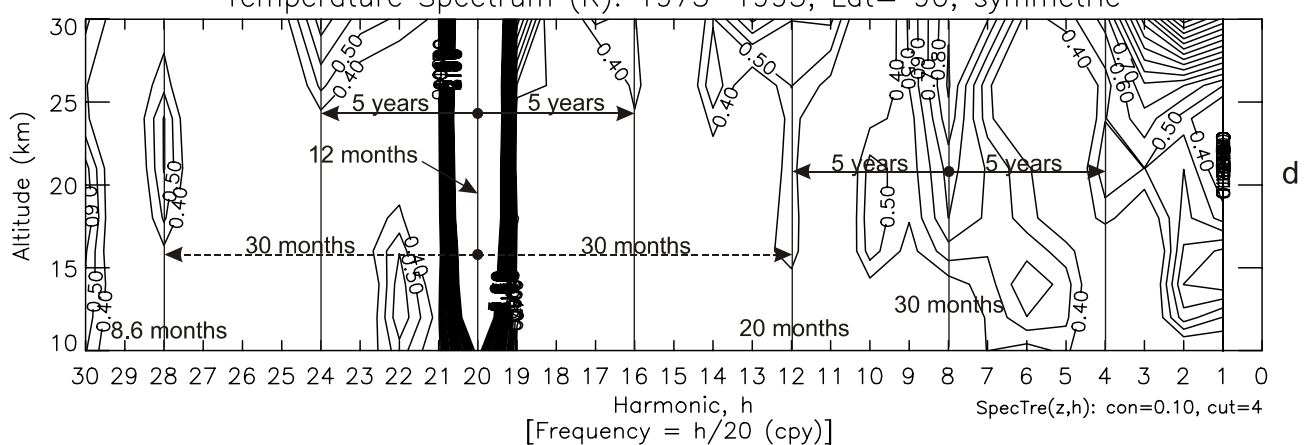

Fig. 1. Amplitude spectra for the temperatures obtained from the NCEP/NCAR R-1 data for 40- and 20-year time spans from 1962 to 2002 and 1975 to 1995, respectively, plotted versus Fourier harmonic, $h$, and altitude. The corresponding frequencies are $h / 40$ and $h / 20$ (cycles per year) and the periods are 40/h and $20 / h$ (years). Shown are the symmetric components at the equator (a, c) and at the pole (b, d), with contour intervals of 0.05 and $0.1 \mathrm{~K}$, respectively, given at the lower right of the figures. To suppress clutter, the lowest four contours are eliminated. Note the spectral features describing the 12-month AO and the dominant QBO with periods of 28.2 (a, b) and 30 (c, d) months, which are prominent also in the zonal wind data (MetAL). With arrows are identified the signatures of the 5-year semi-decadal (SD) oscillations, which modulate the AO and QBO, and they are more pronounced at the pole than at the equator. For the 20-year time span (c, d), where the 30-month QBO dominates, the SD signatures modulating the symmetric AO are larger than those for the 40-year time span (a, b). 
derived, respectively, for the 40- and 20-year NCEP data sets. Applying Fourier analysis, the amplitudes of the spectra are presented in terms of discrete harmonics, $h$, and are plotted versus altitude from 10 to $30 \mathrm{~km}$. For the 20-year data sample (MetAl, Fig. 3), the frequencies are then given by $h / 20$ (cycles per year), and the corresponding periods are $20 / h$ (years). This format is perhaps unusual, but it is convenient for the present purposes where we interpret the results in terms of non-linear interactions. Since the product between complex amplitudes $A \exp \left[i \omega_{A} t\right] \cdot B \exp \left[i \omega_{B} t\right]$ produces $\operatorname{Cexp}\left[i\left(\omega_{A} \pm \omega_{B}\right) t\right]$, the non-linear interactions can be identified in the spectra simply from the additions and subtractions of integers, i.e. $\omega_{A} \pm \omega_{B} \rightarrow h_{A} \pm h_{B}$. Although the derived spectra of the NCEP data may appear complicated, their interpretations prove to be straightforward.

In Fig. 3a (MetAl) for the symmetric zonal wind component at the equator, large amplitude signatures are apparent that describe the QBO, which is dominated by the period of 30 months at $h=8$. And the sharp feature at $h=20$ represents the symmetric 12-month AO. Of interest for the present analysis are the spectral side lobes that describe the 5-year SD modulations as indicated with solid arrows. The feature at $h=16(20-4)$ produces the SD modulation of the AO, and the ones at $h=4$ and $12(8 \pm 4)$ modulate the QBO. These SD modulations are believed to originate from a SD oscillation at $h=4$, which is anti-symmetric as shown in Fig. 3b (MetAl) at 20 degrees latitude. Such an anti-symmetric SD oscillation could interact, through non-linear processes, with the dominant anti-symmetric $\mathrm{AO}$ at $h=20$ to generate the symmetric side lobe at $h=(20-4)$; and it could interact with the symmetric and anti-symmetric QBO at $h=8$ to produce the side lobes at $h=(8 \pm 4)$ as indicated. The distinct anti-symmetric spectral features at $h=12$ and $28(20 \pm 8)$, identified with dashed arrows, represent periods of about 20 and 8.6 months, respectively, which are produced by the nonlinear interaction between the dominant symmetric QBO $(h=8)$ and the strong anti-symmetric $\mathrm{AO}(h=20)$.

For the analyzed 40-year time span in Fig. 1a of MetAl, the QBO is dominated by the period of about 28.2 months at $h=17$, and the side lobe at $h=9(17-8)$ is the signature of the SD modulation. The sharp feature at $h=40$ represents the symmetric 12-month $\mathrm{AO}$, and the signature of its SD modulation appears at $h=32(40-8)$. As seen also in the above-discussed spectra, these modulations originate in the anti-symmetric SD oscillation at $h=8$ as shown in Fig. 1b (MetAl) for 20 degrees latitude. The SD signatures, however, are weaker for this 40 -year data sample where the dominant period of the QBO is not 30 but 28.2 months.

Commensurate with the above-discussed $\mathrm{QBO}$ and $\mathrm{AO}$ zonal wind signatures at the equator (Figs. 1 and 3 of MetAl), the corresponding temperature signatures are also pronounced as seen from Fig. 1 of the present paper. The dominant periods of the temperature QBO are identical to those for the zonal winds. In Fig. 1a, for the 40-year time span, the spectral side lobes are identified at $h=9$ and 25
$(17 \pm 8)$, which modulate the QBO $(h=17)$ with the SD periodicity. At the pole (Fig. 1b), the symmetric QBO signature is also prominent (note the factor of 2 larger contour intervals), and the SD side lobes are evident as well. In that figure, the signature of the symmetric $\mathrm{AO}(h=40)$ is evidently much larger than at the equator, and around $30 \mathrm{~km}$ a side lobe appears to indicate that a stronger SD modulation is developing at higher altitudes. In the anti-symmetric component at high latitudes (not shown), the AO is very large as expected; but there are no discernable signatures of the QBO and SD oscillation.

For the shorter time span of 20 years, with dominant 30-month QBO in Fig. 1c, the spectral features essentially mimic those evident in Fig. 1a. However, the SD modulation of the $\mathrm{AO}$ is now apparent also at the equator, as seen from the side lobe at $h=16(20-4)$. And in the symmetric component at the pole (Fig. 1d), the SD signatures for the AO modulation are more pronounced. The anti-symmetric component at the pole (not shown) again does not reveal a QBO signature, and the SD oscillation is not excited.

In an analysis of Total Ozone Mapping Spectrometer (TOMS) ozone measurements for the years 1978 to 1991, a subset of the 40-year time span in our analysis, Tung and Yang (1994) also showed that the 30-month QBO dominates, and Yang and Tung (1994) found the same in ozone data collected from Dobson stations for the years 1957 to 1986. The 60-month (SD) oscillation is also evident in their spectra. In these papers, the authors furthermore show that the data contain pronounced oscillations with periods of 20 and 8.6 months, which were interpreted to be the signatures of non-linear interactions between the QBO and AO (Hamilton, 1989). Hamilton (1995) extended the ozone spectral analysis of Tung and Yang (1994) by separating the symmetric and anti-symmetric components and found, as in the present paper, that the oscillations with periods of about 20 and 8.4 months can be tied to the QBO interacting with the AO.

In partial support of our interpretation, we present in Fig. 2 the results from a 2-D run of the mechanistic Numerical Spectral Model, which generates the 30-month QBO (Mayr et al., 2003). This model employs the Doppler Spread Parameterization (DSP) for small-scale gravity waves (Hines, 1997a, b), which produces the momentum forcing and the eddy diffusivity, $K$, to generate the QBO. Numerical experiments show that the amplitude and period of the QBO vary with the momentum forcing, and with $K$ in particular, and the parameters for the present solution were chosen from the proposed range of the DSP. In Fig. 2a, the symmetric component of the zonal wind spectrum for 30 model years is shown at $4^{\circ}$ near the equator. The QBO signature evidently dominates and is confined to the sharp spectral feature at $h=12$ for a period of 30 months. And in the anti-symmetric component at $20^{\circ}$ latitude (Fig. 2b), the 12-month AO dominates at $h=30$. As seen from Fig. $2 b$, the model generates the anti-symmetric 5-year SD oscillation at $h=6$, which interacts apparently with the $\mathrm{AO}$ at $h=30$ to generate the symmetric 

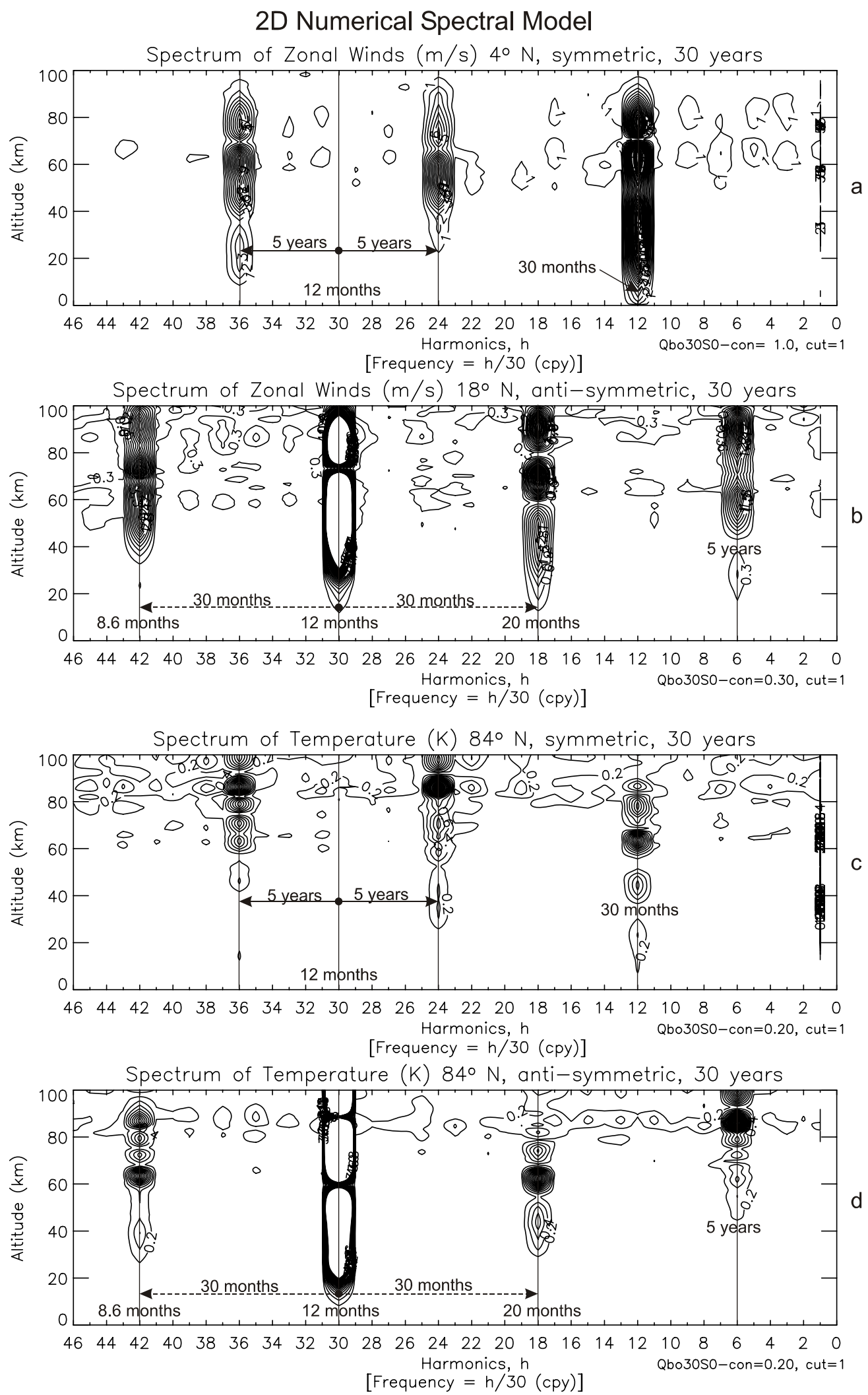

Fig. 2. Spectra from a 2-D mechanistic model (Mayr et al., 2003), which generates the 30-month QBO with SD oscillations. From a 30-year model run, the numerical results are presented for the zonal winds at low latitudes $(\mathbf{a}, \mathbf{b})$, and for the temperature variations near the poles (c, d). All the spectral features can be identified to provide qualitative understanding. 

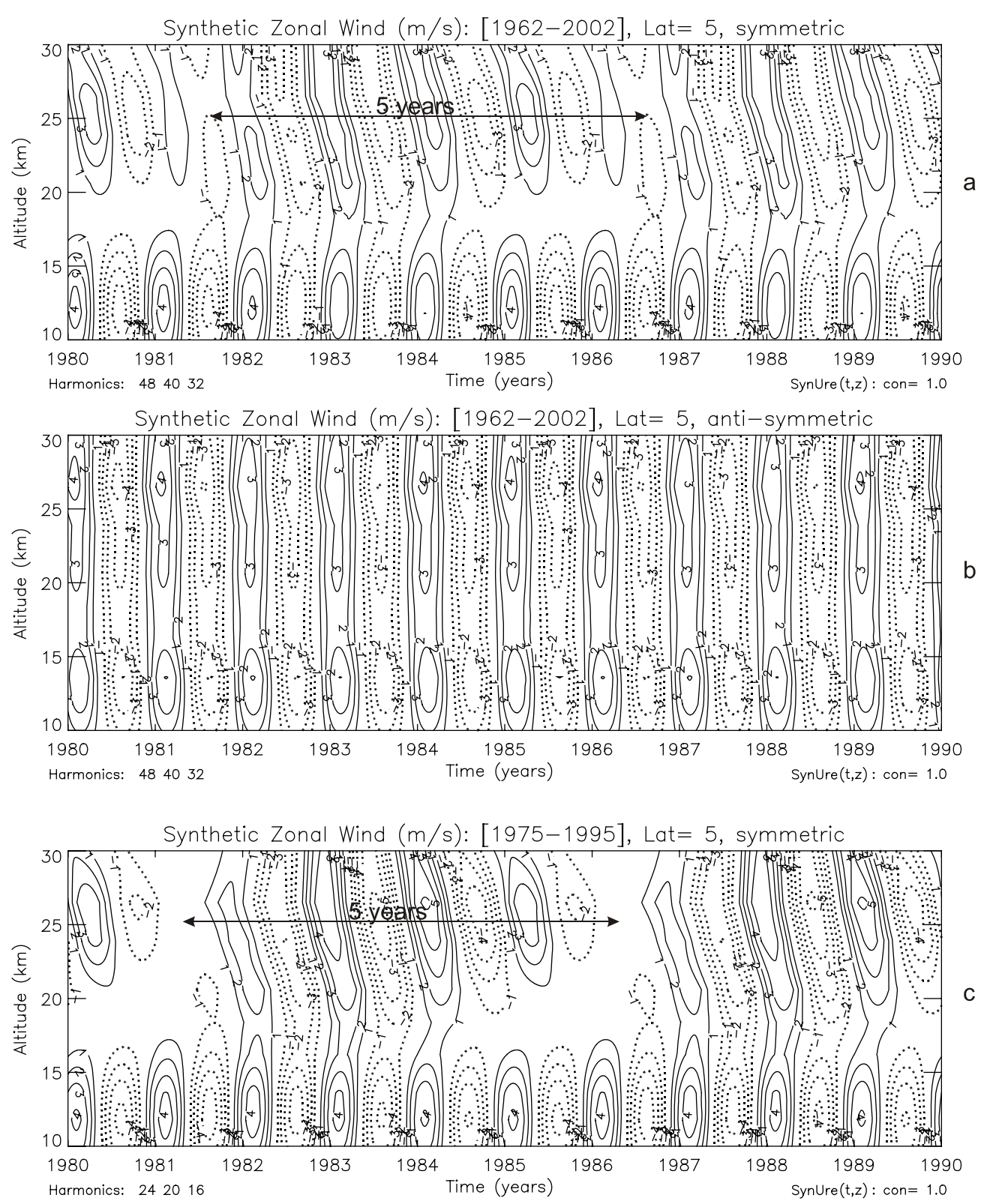

Fig. 3. Synthesized or spectrally filtered zonal winds describe the AO at 5 degrees near the equator for the hemispherically symmetric and anti-symmetric components. For the time span 1962 to 2002 (a, b), the harmonic $h=40$ is synthesized with the SD features at $h=40 \pm 8$ (given at the left bottom) to describe the SD modulation of the AO from 10 to $30 \mathrm{~km}$ plotted versus time from 1980 to 1990 . Although the feature at $h=48(40+8)$ does not appear in the spectrum for the chosen contour intervals, it is accounted for in the synthesis. The symmetric AO (a) slowly propagates down $(\sim 3 \mathrm{~km} /$ month) at altitudes above $15 \mathrm{~km}$, and a pronounced SD modulation is evident, causing the AO amplitude to vary by almost $4 \mathrm{~m} / \mathrm{s}$ near $25 \mathrm{~km}$. The anti-symmetric component (b), in contrast, displays virtually no phase progression with height (i.e. high propagation velocity), and no SD modulation. For the time span 1975 to 1995 (c), the harmonics $h=20$ and $20 \pm 4$ are employed. The SD modulation in (c) is in phase with (a), and it is significantly larger in magnitude. In the anti-symmetric component (not presented) there is again no SD modulation evident, and no phase progression.

side lobes at $h=24$ and $36(30 \pm 6)$. Due to the non-linear interaction between QBO and AO, the periods of 20 and 8.6 months are produced. The spectral features that characterize the zonal winds at low latitudes are also excited in the temperature variations of the polar region (Fig. 2c and d), which are generated in this 2-D model by adiabatic heating and cooling associated with the meridional circulation. Without topography and the related atmospheric variations across the globe, however, this model does not generate the symmetric AO zonal winds near the equator seen in the NCEP 
data at $h=20$ (Fig. 3a of MetAl). The model also does not reproduce the anti-symmetric QBO at $h=8$ (Fig. $3 \mathrm{~b}$ of MetAl), which can interact with the anti-symmetric SD oscillation at $h=8$ to generate in Fig. 3a of MetAl the side lobes at $h=(8 \pm 4)$ that modulate the symmetric QBO in the real world.

\section{Semi-decadal (SD) modulation of the annual oscilla- tion (AO)}

The filtered $\mathrm{AO}$ zonal winds at $5^{\circ} \mathrm{N}$ latitude near the equator are shown in Fig. 3. For the 40-year time span from 1962 to 2002 , we synthesize the harmonics $h=40$ with $h=40 \pm 8$ to describe the 5-year semi-decadal (SD) modulations of the symmetric (Fig. 3a) and anti-symmetric (Fig. 3b) components. Although the symmetric signature at $h=48$ does not appear in the spectrum (Fig. 1a of MetAl) for the chosen contour intervals, it is accounted for in the analysis. In Fig. 3a, a pronounced SD modulation is evident, which peaks at about $25 \mathrm{~km}$ as seen also in the spectrum. At this altitude, the SD oscillation causes the zonal winds to be modulated by almost $4 \mathrm{~m} / \mathrm{s}$, with the largest amplitudes occurring between 1983 and 1984. Although the results are shown only for the years from 1980 to 1990, the displayed pattern of the SD modulation continues to repeat over the entire time span analyzed. The zonal wind pattern in Fig. 3a shows that the symmetric AO slowly propagates down to about $17 \mathrm{~km}$, and the phase velocity is about $3 \mathrm{~km} /$ month. Slow propagation velocities are characteristic of wave-driven equatorial oscillations, like the QBO with about $1.3 \mathrm{~km} /$ month. For the anti-symmetric component (Fig. 3b), in contrast, the AO displays virtually no phase progression with altitude (i.e. large propagation velocity), and the SD modulation is also not evident. Wave interactions in that case are relatively ineffective.

For the shorter time span of 20 years (1975 to 1995), where the 30-month QBO dominates, the filtered SD modulation of the AO is shown in Fig. 3c. Consistent with the differences in the spectra (Figs. 1a and 3a of MetAl), the SD modulation is larger causing the zonal winds to vary by almost $6 \mathrm{~m} / \mathrm{s}$ at $25 \mathrm{~km}$. The peak amplitudes again occur between the years 1983 and 1984 to show that the modulations for the two time spans are essentially in phase. The anti-symmetric component (not presented) again does not reveal any phase progression with altitude or a significant SD modulation, and over the entire altitude range this 12-month $\mathrm{AO}$ is in phase with that from the longer time span.

As seen from Fig. 3d of MetAl, the symmetric AO zonal winds peak at the equator where the SD modulation accounts for amplitude differences of about $3 \mathrm{~m} / \mathrm{s}$ over 5 years. Outside the tropics, the AO sharply increases and peaks at about 60 degrees latitude where the winds reach amplitudes of about $14 \mathrm{~m} / \mathrm{s}$ without being modulated much by the SD oscillation. A close inspection of the zonal winds at this latitude reveals that the weak SD modulation also seems to vary erratically since the patterns for the 40 - and 20 -year time spans are out of phase. This further supports the picture that, for the zonal winds, the SD modulation of the AO is confined to equatorial latitudes.

In the temperature variations, the situation is completely different, and this is shown in Fig. 4a and b, where we present at the equator and pole the height variations of the filtered symmetric AO temperature variations for the time span from 1975 to 1995. As in Fig. 3, the oscillations are generated with the spectral features $h=20$ and $20 \pm 4$. At the equator (Fig. 4a), with contour intervals of $0.5 \mathrm{~K}$, a weak SD modulation of about $0.5 \mathrm{~K}$ is apparent above $20 \mathrm{~km}$ where the amplitude of the AO itself is comparatively small. At the pole (Fig. 4b), with contour intervals of $1 \mathrm{~K}$, the $\mathrm{AO}$ amplitude is close to $8 \mathrm{~K}$, and the SD modulation is then barely discernable although it is much larger than at the equator. The background of the large polar AO amplitude is evidently hiding the SD modulation, and in Fig. $4 \mathrm{c}$ and d, we present an analysis that addresses this problem.

In this analysis, we portray the modulation patterns specifically and separate from the oscillation that is being modulated. The approach is illustrated by applying it to the time series of the large symmetric AO at polar latitudes, which is presented at $31 \mathrm{~km}$ in Fig. 4c. Figure $4 \mathrm{c}$ shows the filtered variations of the $\mathrm{AO}$, with positive phase (solid) and negative phase (dashed), which describe the SD modulation at this altitude. This reveals that the modulation causes the AO to vary from about 5.5 to $7.5 \mathrm{~K}$. The envelope of this modulation (solid line) is computed from the maxima of the positive and negative $\mathrm{AO}$ temperature excursions, and the dotted line at about $6.5 \mathrm{~K}$ represents the time average of the computed envelope. The deviations of this envelope from the mean, about $\pm 1 \mathrm{~K}$, thus describe the magnitude of the modulation. Applying this procedure, we then construct the contour plot (Fig. 4d) that displays the SD modulation of the temperature $\mathrm{AO}$ presented in Fig. 4b. It shows that the symmetric $\mathrm{AO}$ at $30 \mathrm{~km}$ is modulated by about $2 \mathrm{~K}$, with the maximum (positive) occurring between 1982 and 1983 and the minimum (negative) at 1985 . The modulation is also shown propagating down and thus displays in concise form the SD pattern, unaffected by the large magnitude of the $\mathrm{AO}$ amplitude.

The above analysis is applied in Fig. 5 to describe the symmetric SD modulations of the temperature data. For the years 1962 to 2002 , the harmonic $h=40$ is synthesized together with $h=40 \pm 8$ for the equator (Fig. 5a) and pole (Fig. 5b). In Fig. $5 \mathrm{a}$, the $\mathrm{SD}$ modulation at $30 \mathrm{~km}$ produces variations of about $\pm 0.25 \mathrm{~K}$, amounting to temperature differences of more than $0.5 \mathrm{~K}$, with the maximum occurring after 1983. The modulation varies with altitude and produces smaller variations below $20 \mathrm{~km}$. At the pole (Fig. 5b), the SD is larger to yield values of $\pm 0.40 \mathrm{~K}$ near $25 \mathrm{~km}$, revealing a pattern of height variation that is completely different from that displayed at low latitudes (Fig. 5a).

For the shorter time span from 1975 to 1995 , where the 30-month QBO dominates, the harmonics analyzed are $h=20$ with $h=20 \pm 4$, as in Fig. 4, and the results are presented in 

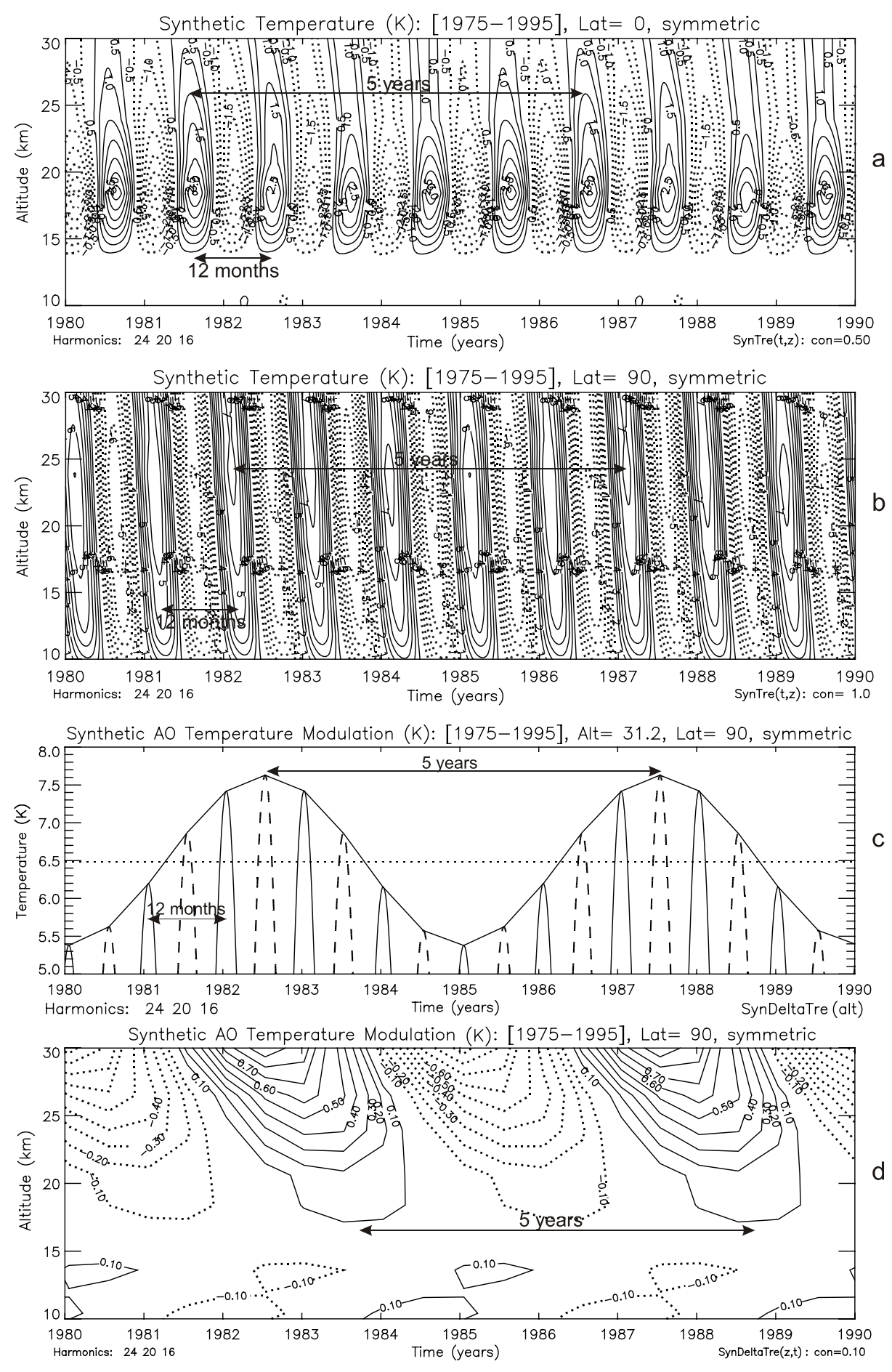

Fig. 4. Similar to Fig. 3c but for the synthesized symmetric temperature variations at the equator (a). The SD modulation above $25 \mathrm{~km}$ is about $0.5 \mathrm{~K}$, and it is distinguishable since the $\mathrm{AO}$ amplitude itself is relatively small. At the pole (b), however, the amplitude of about $7 \mathrm{~K}$ is relatively large, and the magnitude of the modulation is not discernable. When the background oscillation is large, its weak but measurable amplitude modulation must be extracted separately, and the analysis for that is discussed with the subsequent figures (c, d). (c) With reduced temperature excursion, the envelope of the $\mathrm{AO}$ (solid line) describes the $\mathrm{SD}$ modulation (varying from about 5.4 to $7.6 \mathrm{~K}$ ), and the dotted line at $6.5 \mathrm{~K}$ represents the time average. The deviations of the envelope from the mean are applied to construct the contour plot in (d), which describes in concise form the SD modulation of the AO presented in (b). Without being masked by the large AO amplitude that is effectively hiding the SD in (b), the contour plot in (d) shows that the modulation amounts to variations of about $2 \mathrm{~K}$ at $30 \mathrm{~km}$, with the maximum occurring between 1982 and 1983 and the minimum at 1985. It also shows that the magnitude of the SD modulation is largest at $30 \mathrm{~km}$ and propagates down to lower altitudes. 

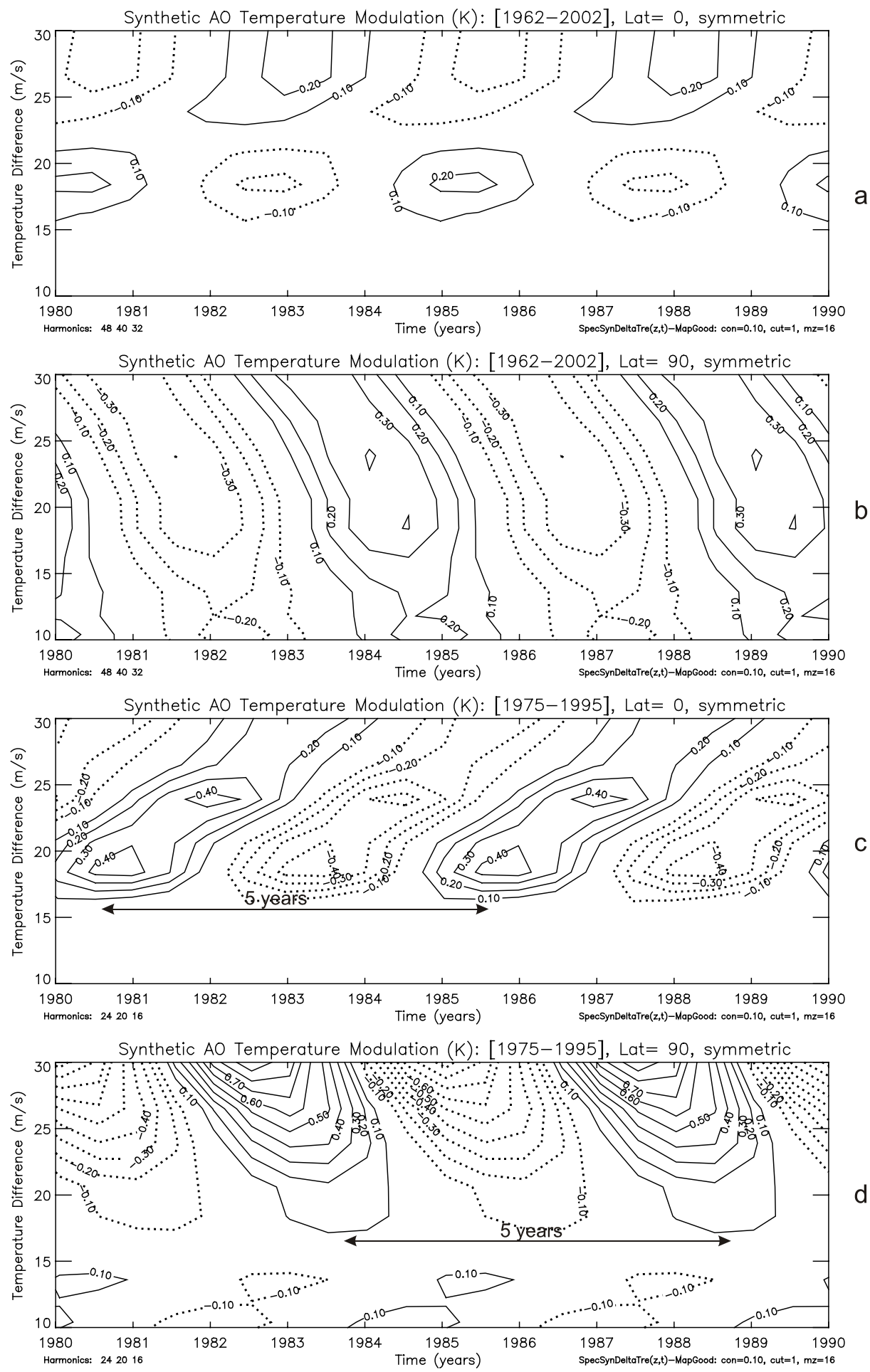

Fig. 5. Applying the analysis discussed in Fig. $4 \mathrm{c}$ and d, the synthesized (filtered) SD modulations of the 12-month AO are presented for the equator and pole based on data covering the years 1962 to 2002 (a, b) and 1975 to 1995 (c, d). The contour interval is $0.1 \mathrm{~K}$. (a) For the 40-year time span at the equator, the SD temperature modulation produces variations of about $0.5 \mathrm{~K}( \pm 0.25 \mathrm{~K})$ at $30 \mathrm{~km}$, and somewhat smaller and more isolated variations close to $20 \mathrm{~km}$. At the pole (b), the modulation amplitude is larger to generate variations of about $0.8 \mathrm{~K}$ near $25 \mathrm{~km}$. For the shorter time span of 20 years, the SD temperature modulation at the equator (c) reveals a pattern that resembles the one shown in (a). The amplitude and phase at $30 \mathrm{~km}$ almost agree, and the modulation is also shifted to earlier times at lower altitudes. However, the modulation pattern at the pole (d) is significantly different from that displayed in (b), and its magnitude is much larger at altitudes above $20 \mathrm{~km}$. 
Fig. $5 \mathrm{c}$ for the equator and in Fig. $5 \mathrm{~d}$ for the pole (identical to Fig. 4d). At the equator, the SD pattern in Fig. 5c resembles the one for the longer time span in Fig. 5a. The modulations almost agree in amplitude and phase at $30 \mathrm{~km}$, and the height variations in both cases produce patterns in which the maxima occur after 1980 at altitudes below $20 \mathrm{~km}$. For the pole, however, the displayed SD modulation in Fig. 5d is qualitatively different from that shown in Fig. 5b. Unlike the pattern for the longer time span, the SD produces relatively large temperature variations of about $2 \mathrm{~K}$ at $30 \mathrm{~km}$, but the modulations decay more rapidly at lower altitudes.

\section{Semi-decadal (SD) modulation of the quasi-biennial oscillation (QBO)}

Considering the spectral features that describe the SD modulations of the QBO zonal winds in Fig. 1a of MetAl, we present with Fig. 6 the synthesized variations for the years 1962 to 2002 near the equator. For this 40-year time span, with dominant QBO of 28.2 months, the harmonic $h=17$ is synthesized with $h=17 \pm 8$ to produce in Fig. 6a the hemispherically symmetric oscillations plotted versus altitude from 15 to $30 \mathrm{~km}$, applying contours intervals of $2 \mathrm{~m} / \mathrm{s}$. The resulting alternating wind velocities are close to $15 \mathrm{~m} / \mathrm{s}$ and show a pronounced SD modulation. To reveal that modulation explicitly, we present in Fig. $6 \mathrm{~b}$ the results from our analysis above discussed. Instead of computing the AO modulation as in Fig. 4d, the analysis is applied to the QBO to produce the contour plot in Fig. $6 \mathrm{~b}$. This shows that the SD oscillation modulates the QBO at altitudes close to $24 \mathrm{~km}$ by about $\pm 2.5 \mathrm{~m} / \mathrm{s}$ to produce variations of about $5 \mathrm{~m} / \mathrm{s}$ at that altitude. Though smaller in magnitude, the variations are also significant at $30 \mathrm{~km}$. For comparison, we present in Fig. 6c the anti-symmetric component of the QBO wind velocities at 5 degrees latitude. With contour interval of $0.1 \mathrm{~m} / \mathrm{s}$, the amplitudes are small compared to those shown in Fig. 6a. Moreover, the displayed pattern reveals that there is virtually no phase progression with altitude in the anti-symmetric component of the QBO, much like the AO presented in Fig. 3b. The QBO results, like those for the AO, thus emphasize again the close connection between hemispherical symmetry and the efficient wave forcing with slow phase progression at equatorial latitudes. The analysis results for the 20-year time span (not presented), where the 30-month QBO dominates, reveal that the amplitudes are larger, close to $20 \mathrm{~m} / \mathrm{s}$ at around $26 \mathrm{~km}$. But the SD modulation of the QBO is somewhat weaker. At $24 \mathrm{~km}$, the SD modulation causes the amplitudes to vary by about $4 \mathrm{~m} / \mathrm{s}$, and the modulation maximum occurs close to 1981 where it also occurs in Fig. 6b. However, at higher altitudes where the effect is weaker, the phase of the SD modulation for the 20-year time span is almost opposite to that shown in Fig. $6 \mathrm{~b}$.

For the QBO temperature variations, we present in Fig. 7 the SD modulations derived from the 40 -year data span cov- ering the years 1962 to 2002. Employing the harmonics $h=9$, 17, 25 as in Fig. 6, the synthesized or filtered variations for the symmetric component are shown at the equator in Fig. 7a. The amplitudes are about $1.5 \mathrm{~K}$ near $25 \mathrm{~km}$ where the temperature QBO peaks. The relatively small SD modulation is then presented in Fig. 7b, which reveals variations between minimum and maximum amplitudes as large as $1 \mathrm{~K}$ at $30 \mathrm{~km}$ and smaller values of about $0.6 \mathrm{~K}$ at about $18 \mathrm{~km}$ altitude. In the polar region (Fig. 7c), the SD modulation at $18 \mathrm{~km}$ produces amplitude differences of about $1 \mathrm{~K}$ as seen also from Fig. 7d. Unlike the QBO temperature variations at the equator, the SD modulated oscillations extend down to $10 \mathrm{~km}$ and below.

To reveal the latitudinal temperature variations, Fig. 8a shows near $18 \mathrm{~km}$ a synthesis of the harmonics $h=9,17,25$, which represent the symmetric and anti-symmetric (or total) spectral features that characterize the SD modulation for the 40-year time span covering the years 1962 to 2002. Around the equator, the maximum and minimum temperature amplitudes are, respectively, close to $1.2 \mathrm{~K}$ and $0.6 \mathrm{~K}$ to produce a $\mathrm{SD}$ modulation of about $0.6 \mathrm{~K}$. At the poles in the Northern and Southern Hemispheres, the SD temperature signatures are different to indicate that the anti-symmetric component is important. As seen at the poles in the two hemispheres, symmetry is also on display for example in the negative and positive phase patterns during the years 1981 and 1982, respectively, which are opposite in phase to the equatorial oscillations. For the years 1975 to 1995 in Fig. 8b, the harmonics $h=4,8,12$ are employed to describe the SD modulation of the 30-month QBO that dominates in this case. Figure 8a and $\mathrm{b}$ shows that the maxima and minima in the QBO temperature variations around the equator are essentially in phase. In the polar regions, the temperature patterns also reveal similarities, but the differences are larger.

\section{Summary and conclusion}

An initial analysis of the NCEP zonal wind and temperature data in the stratosphere revealed a pronounced component of the AO, which is hemispherically symmetric and is modulated by a 5 -year semi-decadal (SD) oscillation at equatorial latitudes as reported in Mayr et al. (2007, referred to as MetAl). Observational evidence indicates that the SD oscillation is generated by the 30-month QBO. In the present paper, we describe more fully the SD modulations that appear in the symmetric $\mathrm{AO}$ and $\mathrm{QBO}$ and extend in the temperature to the polar regions.

As in MetAl, the data analysis is applied to time spans of 40 years (1962 to 2002) and 20 years (1975 to 1995), with the latter covering a period where the 30-month QBO dominates. For these time spans, the amplitude spectra of the symmetric zonal winds in Figs. 1a and 3a of MetAl reveal pronounced SD signatures that modulate the AO and QBO. These features originate apparently in the SD oscillations of 

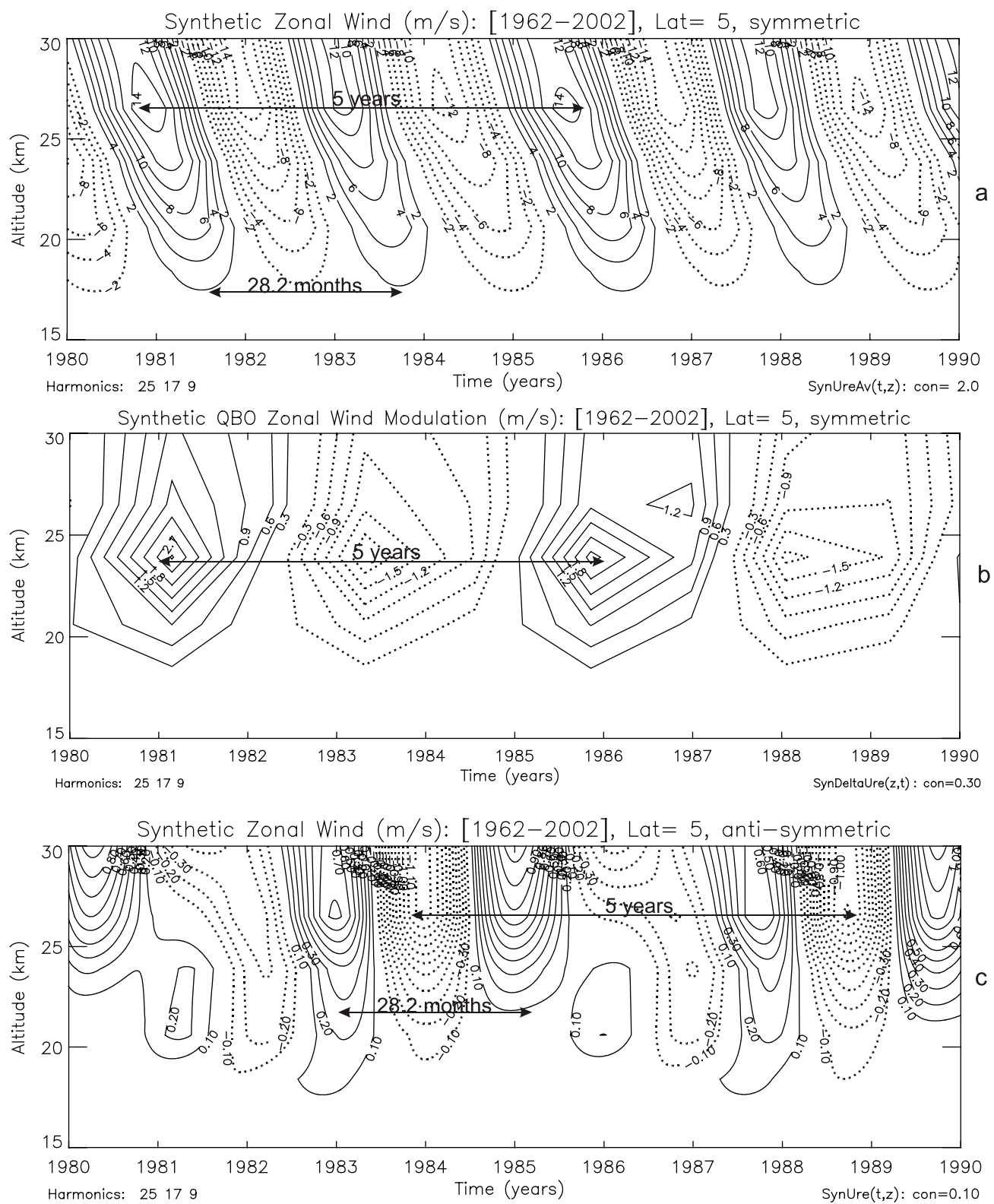

Fig. 6. Synthesized height variations for the QBO zonal winds and their SD modulations near the equator for the years 1962 to 2002 . The harmonics $h=17$ with $17 \pm 8$ describe the SD modulation of the dominant 28.2-month QBO. For the symmetric component (a), the contour intervals are $2 \mathrm{~m} / \mathrm{s}$. The maximum amplitudes are close to $15 \mathrm{~m} / \mathrm{s}$, and the SD modulation is apparent. Applying the analysis discussed with Fig. 4c and d, but for the QBO instead of AO, the computed SD modulation is presented in (b). This shows that the wind amplitudes vary over a period of 5 years by as much as $5 \mathrm{~m} / \mathrm{s}$ at about $24 \mathrm{~km}$, with the maximum occurring close to the year 1981. At higher altitudes, the modulation is weaker but still significant. For the small anti-symmetric component near the equator with contour intervals of $0.1 \mathrm{~m} / \mathrm{s}$ (c), the QBO displays virtually no phase progression with height, like the AO in Fig. 3b.

the anti-symmetric wind component evident in Figs. $1 \mathrm{~b}$ and $3 \mathrm{~b}$ of MetAl. As shown in MetAl (Figs. 1c, 3d), the SD modulated symmetric $\mathrm{AO}$ wind component peaks at the equator. Outside the tropics, the winds then increase to reach the primary maximum at about $60^{\circ}$ latitude; but the SD modulations at that latitude are small.
The temperature spectra (Fig. 1) also contain pronounced signatures of the 12-month $\mathrm{AO}$ and $\mathrm{QBO}$. In contrast to the zonal winds, however, the symmetric temperatures exhibit SD oscillations at higher latitudes and in the polar regions (Fig. $1 \mathrm{~b}$ and $\mathrm{d}$ ), where the spectral signatures are about a factor of two larger than those at the equator (note the differences in contour intervals). In the anti-symmetric 

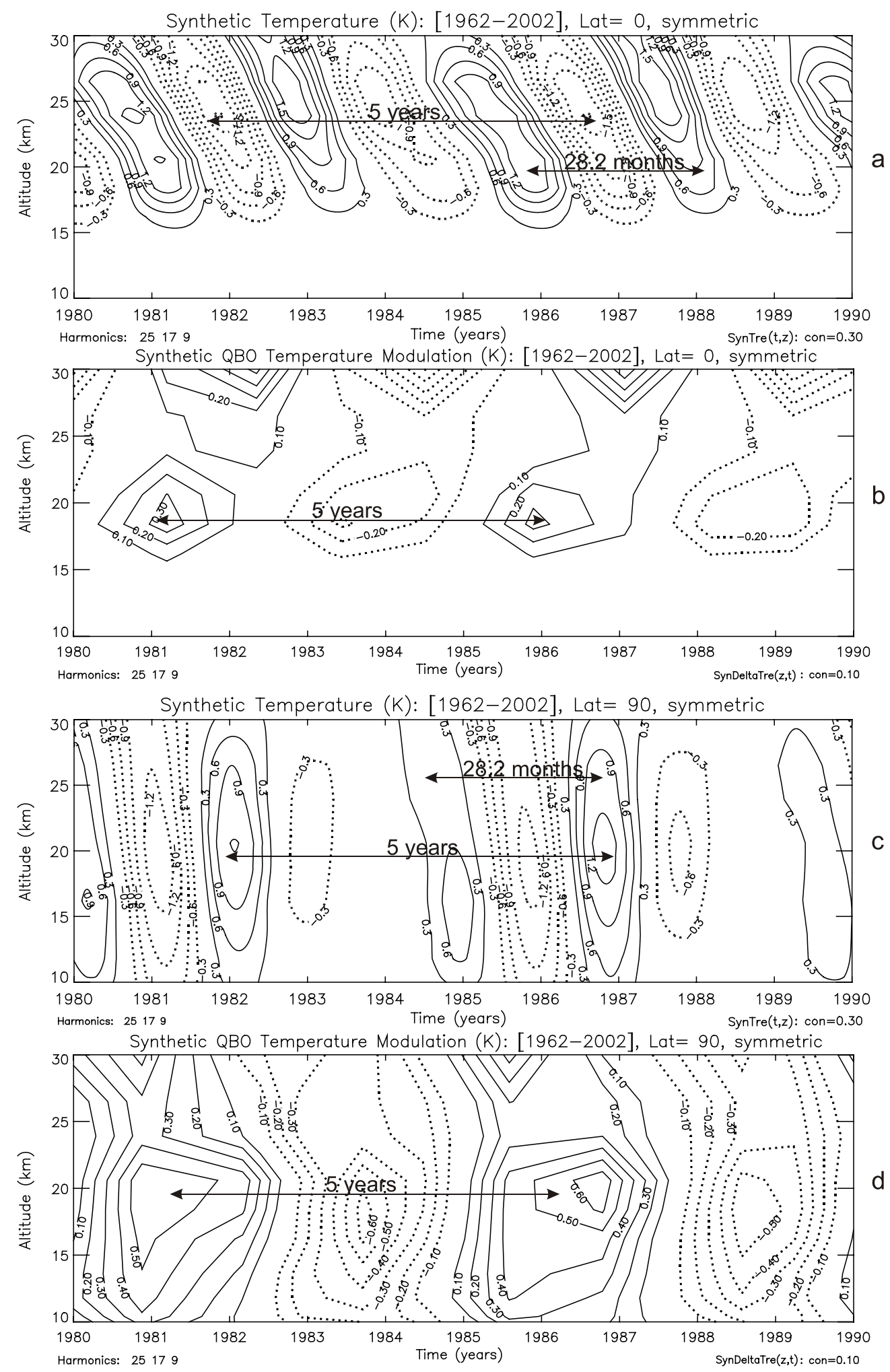

Fig. 7. Synthesized height variations of the QBO temperature variations and their SD modulations for the years 1962 to 2002 . The harmonics $h=17$ with $17 \pm 8$ are employed. For the equator, we present in (a) the QBO height variations and in (b) their SD modulations, which reveal amplitude differences exceeding $0.5 \mathrm{~K}$ at about $18 \mathrm{~km}$ and still larger values at $30 \mathrm{~km}$. Analogous to (a, b), the QBO temperature variations at the pole are shown in (c) and their embedded SD modulations in (d), which exhibit amplitude variations of about $1 \mathrm{~K} \mathrm{near} 20 \mathrm{~km}$. 

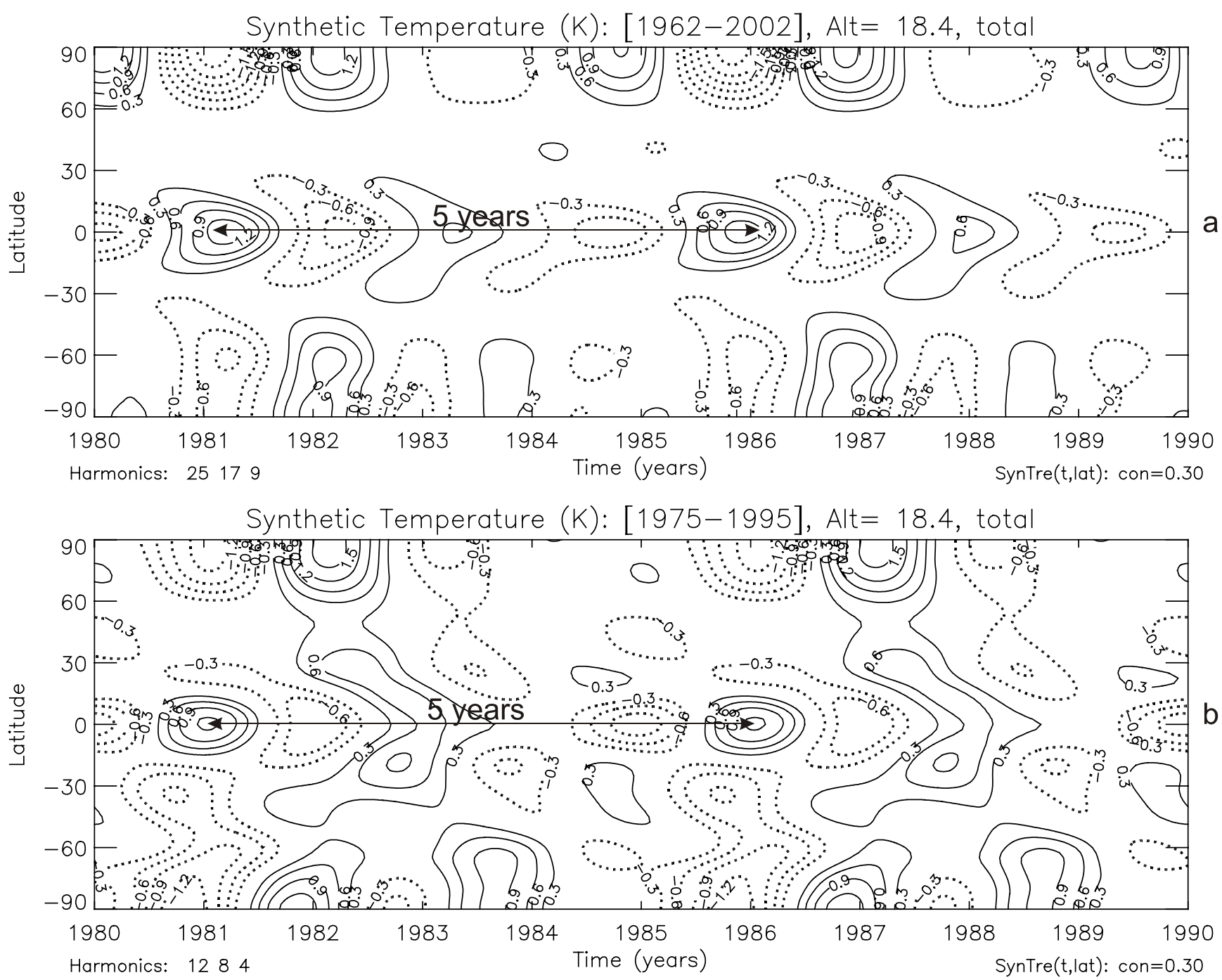

Fig. 8. Latitudinal variations of the synthesized QBO temperature variations near $18 \mathrm{~km}$ altitude, describing the SD modulation for the time spans 1962 to 2002 (a) and 1975 to 1995 (b). In the latter shorter time span, the 30-month QBO dominates. The symmetric and anti-symmetric (total) spectral features are employed for the harmonics $h=9,17,25$ (a) and $h=4,8,12$ (b), and the contour interval is $0.3 \mathrm{~K}$. Around the equator, the magnitude of the SD modulation accounts for amplitude differences of about $0.5 \mathrm{~K}$ over a period of 5 years. At the poles, the differences are about a factor of two larger. While the polar regions in the two hemispheres show differences to indicate that the anti-symmetric component is important, symmetry is also on display for example during the years 1981, 1982 and 1986, 1987, where the oscillations are in phase in both hemispheres.

temperature component of the polar region (not presented), the 12-month AO is very large, but there are no signatures of the QBO and SD oscillation.

The pivotal role of wave forcing evident in the NCEP data is illustrated in Fig. 3, where we present the synthesis for the harmonics that describe the SD modulations of the 12 -month AO. At altitudes above $17 \mathrm{~km}$, the symmetric AO slowly propagates down with a phase speed of about $3 \mathrm{~km} / \mathrm{month}$, and the SD modulation accounts for amplitude variations as large as $5 \mathrm{~m} / \mathrm{s}$. In the anti-symmetric component, in contrast, there is virtually no phase progression evi- dent owing to the lack of effective wave forcing in that case, and the SD modulation is weak. These characteristics of the NCEP data are in qualitative agreement with the model results from a solar cycle (SC) study (Mayr et al., 2005), which shows that the modulated symmetric AO zonal winds propagate down through the stratosphere with a velocity of about $3 \mathrm{~km} /$ month, thus carrying the SC signature to lower altitudes. The anti-symmetric AO component from the model also does not reveal a phase progression with altitude, and not a SC modulation either. 
In the NCEP data, a relatively weak SD modulation is seen in the symmetric $\mathrm{AO}$ temperature variations at equatorial latitudes (Fig. 5a and c). But the SD modulation is sizable in the polar regions (Fig. 5b and d), where it can account for amplitude variations between 1 and $2 \mathrm{~K}$ in the lower stratosphere. The high-latitude temperature signatures are apparently generated by the meridional circulation and planetary waves, which redistribute the energy globally to focus it partially onto the polar regions. Although the temperature signatures in the data and model results are larger at the poles, we believe that they originate in the equatorial region where most of the energy resides and where the wave forcing is most effective in amplifying the oscillations.

This picture of the observed symmetric AO emerges also from the NCEP results for the QBO. The symmetric QBO zonal wind oscillation near the equator (Fig. 6), with velocities close to $15 \mathrm{~m} / \mathrm{s}$, slowly propagates down at a rate of about $1.2 \mathrm{~km} /$ month, and the SD modulation peaks at about $24 \mathrm{~km}$ where the 5-year amplitude variation amounts to about $4 \mathrm{~m} / \mathrm{s}$. As in Fig. 3b for the AO, the anti-symmetric QBO in Fig. 6c does not reveal a phase progression with altitude, absent efficient wave forcing, and for the same reason, the amplitudes are small (note the small contour interval of $0.1 \mathrm{~m} / \mathrm{s}$ ). In the temperature variations of the QBO (Figs. 7 and 8), like those for the $\mathrm{AO}$ (Fig. 5), the symmetric SD modulations are larger at the poles than at the equator. This is again consistent with our contention that the energy, redistributed by the meridional winds and planetary waves, is partially focused onto the polar regions so as to increase the magnitude of the temperature oscillations, which is shown also in the model results (Mayr et al., 2000).

It was demonstrated with a mechanistic 2-D model (Mayr et al., 2000, 2003) that the SD oscillation in the stratosphere can be generated by a 30-month QBO interacting with the dominant anti-symmetric 12-month $\mathrm{AO}$, and gravity wave node filtering was proposed for the mechanism involved. As shown in Fig. 2, such a model reproduces qualitatively the major spectral features seen in the NCEP data. Mayr et al. (2000) argued that the 30-month QBO appears to be unique in that it is optimally synchronized by the SAO that acts as pacemaker. This synchronization apparently accounts for the stability of the 30-month QBO, evident in the sharp spectral features in Fig. 2, and it may account for the observation that this QBO periodicity and its SD spin-off are important features of the stratospheric climatology.

Acknowledgements. The authors are indebted to two anonymous referees for critical and valuable comments, which contributed significantly to improve the paper.

Topical Editor U.-P. Hoppe thanks two anonymous referees for their help in evaluating this paper.

\section{References}

Baldwin, M. P., Gray, L. J., Dunkerton, T. J., Hamilton, K., Haynes, P. H., Randel, W. J., Holton, J. R., Alexander, M. J., Hirota, I., Horinouchi, T., Jones, D. B. A., Kinnersley, J. S., Marquardt, C., Sato, K., and Takahashi, M.: The quasi-biennial oscillation, Rev. Geophys., 39, 179-230, 2001.

Dunkerton, T. J.: On the role of the Kelvin wave in the westerly phase of the semiannual zonal wind oscillation, J. Atmos. Sci., 36, 32-41, 1979.

Dunkerton, T. J.: Theory of the mesopause semiannual oscillations, J. Atmos. Sci., 39, 2681-2690, 1982.

Dunkerton, T. J.: A two-dimensional model of the quasi-biennial oscillation, J. Atmos. Sci., 42, 1151-1160, 1985.

Fleming, E. L., Chandra, S., Barnett, J. J., and Comey, M.: Zonal mean temperature, pressure, zonal wind, and geopotential height as functions of latitude, COSPAR International Reference Atmosphere: 1986, Part II: Middle Atmosphere Models, Adv. Space Res., 10, 11-59, 1990.

Giorgetta, M. A., Manzini, E., and Roeckner, E.: Forcing of the quasi-biennial oscillation from a broad spectrum of atmospheric waves, Geophys. Res. Lett., 29(8), 1245-1249, doi:10.1029/2002GL014756, 2002.

Hamilton, K.: Dynamics of the stratospheric semi-annual oscillation, J. Meteorol. Soc. Japan., 64, 227-244, 1986.

Hamilton, K.: Interhemispheric asymmetry and annual synchronization of the ozone quasi-biennial oscillation, J. Atmos. Sci., 46, 1019-1025, 1989.

Hamilton, K.: Comment on "Global QBO in circulation of ozone. Part I: Reexamination of observational evidence”, J. Atmos. Sci., 52, 1834-1838, 1995.

Hamilton, K., Wilson, R. J., and Hemler, R. S.: Spontaneous stratospheric QBO-like oscillations simulated by the GFDL SKYHI general circulation model, J. Atmos. Sci., 58, 3271-3292, 2001.

Haynes, P. H.: The latitudinal structure of the quasi-biennial oscillation, Q. J. Roy. Meteorol. Soc., 124, 2645-2670, 1998.

Hines, C. O.: Doppler-spread parameterization of gravity-wave momentum deposition in the middle atmosphere, 1 , Basic formulation, J. Atmos. Solar Terr. Phys., 59, 371-386, 1997 a.

Hines, C. O.: Doppler-spread parameterization of gravity-wave momentum deposition in the middle atmosphere, 2, Broad and quasi monochromatic spectra, and implementation, J. Atmos. Solar Terr. Phys., 59, 387-400, $1997 \mathrm{~b}$.

Hirota, I.: Observational evidence of the semiannual oscillation in the tropical middle atmosphere - A review, Pure Appl. Geophys., 118, 217-238, 1980.

Hitchman, M. H. and Leovy, C. B.: Estimation of the Kelvin wave contribution to the semiannual oscillation, J. Atmos. Sci., 45, 1462-1475, 1988.

Holton, J. R. and Lindzen, R. S.: An updated theory for the quasibiennial cycle of the tropical stratosphere, J. Atmos. Sci., 29, 1076-1080, 1972.

Huesmann, A. S. and Hitchman, M. H.: The 1978 shift in the NCEP reanalysis stratospheric quasi-biennial oscillation, Geophys. Res. Lett., 30, 1048, doi:10.1029/2002GL016323, 2003.

Huesmann, A. S. and Hitchman, M. H.: The stratospheric quasibiennial oscillation in the NCEP reanalysis: Climatological structure, J. Geophys. Res., 106, 11 859-11 874, 2001.

Kalnay, E.: Atmospheric modeling, data assimilation and predictability, Cambridge University Press, Cambridge, UK, 2003. 
Kalnay, E., Kanamitsu, M., Kistler, R., et al.: THE NCEP/NCAR 40-year reanalysis project, B. Am. Meteorol. Soc., 77, 437-471, 1996.

Levitus, S., Antonov, J. I., Wang, J., Delworth, T. I., Dixon, K. W., and Broccoli, A. J.: Anthropogenic warming of Earth's climate system, Science, 292, 267-270, 2001.

Lindzen, R. S. and Holton, J. R.: A theory of the quasi-biennial oscillation, J. Atmos. Sci., 25, 1095-1107, 1968.

Lindzen, R. S.: Turbulence and stress due to gravity wave and tidal breakdown, J. Geophys. Res., 86, 9707-9714, 1981.

Mayr, H. G., Mengel, J. G., Reddy, C. A., Chan, K. L., and Porter, H. S.: Properties of QBO and SAO generated by gravity waves, J. Atmos. Solar Terr. Phys., 62, 1135-1154, 2000.

Mayr, H. G., Mengel, J. G., Drob, D. P., Chan, K. L., and Porter, H. S.: Modeling studies with QBO: II, Solar cycle effect, J. Atmos. Solar Terr. Phys., 65, 901-916, 2003.

Mayr, H. G., Mengel, J. G., and Wolff, C. L.: Wave-driven equatorial annual oscillation induced and modulated by the solar cycle, Geophys. Res. Lett., 32, L20811, doi:10.1029/2005GL023090, 2005.

Mayr, H. G., Mengel, J. G., Huang, F. T., and Nash, E. R.: Equatorial annual oscillation with QBO-driven 5-year modulation in NCEP data, Ann. Geophys., 25, 37-45, 2007, http://www.ann-geophys.net/25/37/2007/.

Mengel, J. G., Mayr, H. G., Chan, K. L., Hines, C. O., Reddy, C. A., Arnold, N. F., and Porter, H. S.: Equatorial oscillations in the middle atmosphere generated by small scale gravity waves, Geophys. Res. Lett., 22, 3027-3030, 1995.

Pascoe, C. L., Gray, L. C., Crooks, S. A., Jukes, M. N., and Baldwin, M. P.: The quasi-biennial oscillation: Analysis using ERA-40 data, J. Geophys. Res., 110, D08105, doi:101029/2004JD004941, 2005.

Pawson, S. and Fiorino, M. A.: Comparison of reanalysis in the tropical stratosphere. Part 1: Thermal structure and the annual cycle, Clim. Dynam., 14, 631-644, 1998.

Plumb, R. A.: The interaction of two internal waves with the mean flow: Implications for the theory of the quasi-biennial oscillation, J. Atmos. Sci., 34, 1847-1858, 1977.
Reddy, C. A. and Vijayan, L.: Annual and semiannual oscillations in the equatorial middle atmospheric winds, Adv. Space Res., 13(1), 372-376, 1993.

Reddy, C. A. and Reddi, C. R.: Longitudinal differences and interannual variations of zonal wind in the tropical stratosphere and troposphere, J. Atmos. Terr. Phys., 48, 1085-1092, 1986.

Reddy, C. A., Reddi, C. R., and Mohankumar, K. G.: Zonal wind components in the stratosphere and troposphere over India, Q. J. Meteorol. Soc., 112, 811-823, 1986.

Reed, R. J.: The quasi-biennial oscillation of the atmosphere between 30 and $50 \mathrm{~km}$ over Ascension Island, J. Atmos. Sci., 22, 331-333, 1965.

Reed, R. J. and Vlcek, C. L.: The annual temperature variation in the lower tropical stratosphere, J. Atmos. Sci., 26, 163-167, 1969.

Salby, M. and Callaghan, P.: Relationship of the quasi-biennial oscillation in the stratospheric signature of the solar cycle, J. Geophys. Res., 111, D06110, doi:10.1029/2005JD006012, 2006.

Takahashi, M.: Simulation of the quasi-biennial oscillation in a general circulation model, Geophys. Res. Lett., 26 , 1307-1310, 1999.

Thompson, D. W. and Wallace, J. M.: Regional climate impacts of the northern hemisphere annular mode, Science, 293, 85-89, 2001.

Trenberth, K. E.: The definition of El Niño, B. Am. Meteorol. Soc., 78, 2771-2777, 1997.

Trenberth, K. E., Fasullo, J., and Smith, L.: Trends and variability in column-integrated atmospheric water vapor, Clim. Dynam., 24, 741-758, 2005.

Tung, K. K. and Yang, H.: Global QBO in circulation and ozone. Part I: Reexamination of observational evidence, J. Atmos., Sci. 51, 2699-2707, 1994.

Wang, B.: Interdecadal changes in El Niño onset in the last four decades, J. Climate, 8, 267-285, 1995.

Yanai, M. and Tomita, T.: Seasonal and interannual variability of atmospheric heat sources and moisture sinks as determined from NCEP-NCAR Reanalysis, J. Climate, 11, 463-581, 1998.

Yang, H. and Tung, K. K.: Statistical significance and pattern of tropical QBO in column ozone, Geophys. Res. Lett., 21, 22352238, 1994. 